\title{
Salmonella Enteritidis Empyema Preceding the Diagnosis of Non-Hodgkin's Lymphoma and Subsequent Contralateral Chylothorax Treated with Radiolabeled Rituximab
}

\author{
Syed Ali, Muhammad Redzwan S. Rashid Ali, Gary Yun Chor Lee
}

Department of Respiratory Medicine, Sir Charles Gairdner Hospital, Perth, Western Australia

\begin{abstract}
Salmonella infection is common, but pleural involvement has rarely been reported. Only seven cases of Salmonella enteritidis pleural empyema have been reported; all had an associated preexisting underlying immunosuppresion or malignancy. We report the case of an apparently healthy man who developed S. enteritidis empyema. On further follow-up and surveillance, he eventually presented with non-Hodgkin's lymphoma and a contralateral recurrent chylothorax. The latter was successfully controlled with radiolabeled rituximab, which has never been described for the above purpose in literature before.

Keywords: Empyema, chylothorax, lymphoma, radiolabeled iodine, rituximab, Salmonella
\end{abstract}

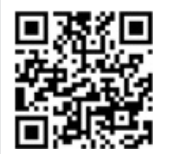

Received Date: 12.04 .2015 Accepted Date: 06.07.2015 Available Online Date: 09.11 .2015 DOI: $10.5152 /$ ejp.2015.99609

Corresponding Author

Muhammad Redzwan S. Rashid Ali

E-mail: redzwanrashid@gmail.com

- Available online at www.eurasianjpulmonol.com

(1) This work is licensed under a Creative Commons Attribution-NonCommercis 4.0 International License.

\section{INTRODUCTION}

Salmonella infection is common; Salmonella enteritidis is among the most common cause of food poisoning in the United States, but presentation with focal pleuropulmonary diseases is uncommon (1, 2). Only seven cases of $S$. enteritidis pleural empyema have been reported; six had a known intra-abdominal infection, malignancy, or lupus. In a review of 1,543 non-typhoid Salmonellosis patients, focal infections were strongly associated with immunosuppression or existing underlying illnesses, including malignancies such as lymphoma.

We report the case of an apparently healthy man who developed S. enteritidis empyema. Kept under surveillance, he eventually presented with non-Hodgkin's lymphoma and a contralateral chylothorax. The latter was successfully controlled with radiolabeled rituximab.

\section{CASE PRESENTATION}

A 57-year-old previously fit man presented with a three-day history of dyspnea. He had no risk factors for immunosuppression. He visited Bali one month prior and had diarrhea then. He was febrile and tachycardic at presentation. Peripheral blood showed neutrophilic leukocytosis $24.8 \times 10^{9} / \mathrm{L}$, raised C-reactive protein $(413 \mathrm{mg} / \mathrm{L}$ ) level, and mildly deranged liver functions. His chest radiograph revealed a left-sided pleural effusion. Computerised tomography demonstrated a multi-loculated effusion, pleural thickening, and mild intrapulmonary and intra-abdominal lymphadenopathy. The drained fluid (1.9 L) was turbid and contained S. enteritidis; no malignant cells were found. Blood, stool, and urine cultures were sterile.

His empyema was successfully treated with intravenous piperacillin-tazobactam and intrapleural streptokinase. A repeat CT scan two months later showed resolution of his empyema and intrapulmonary lymphadenopathy but persistent mild retroperitoneal/mesenteric adenopathy and two tiny omental nodules. Gastroscopy and colonoscopy showed no malignancies. A provisional diagnosis of mesenteric panniculitis was made.

Eleven months after the initial empyema, he presented with breathlessness and a right-sided effusion (Figure 1). On pleuroscopy, 1.5 L of chylous, triglyceride-rich fluid was removed. The fluid and pleu- 

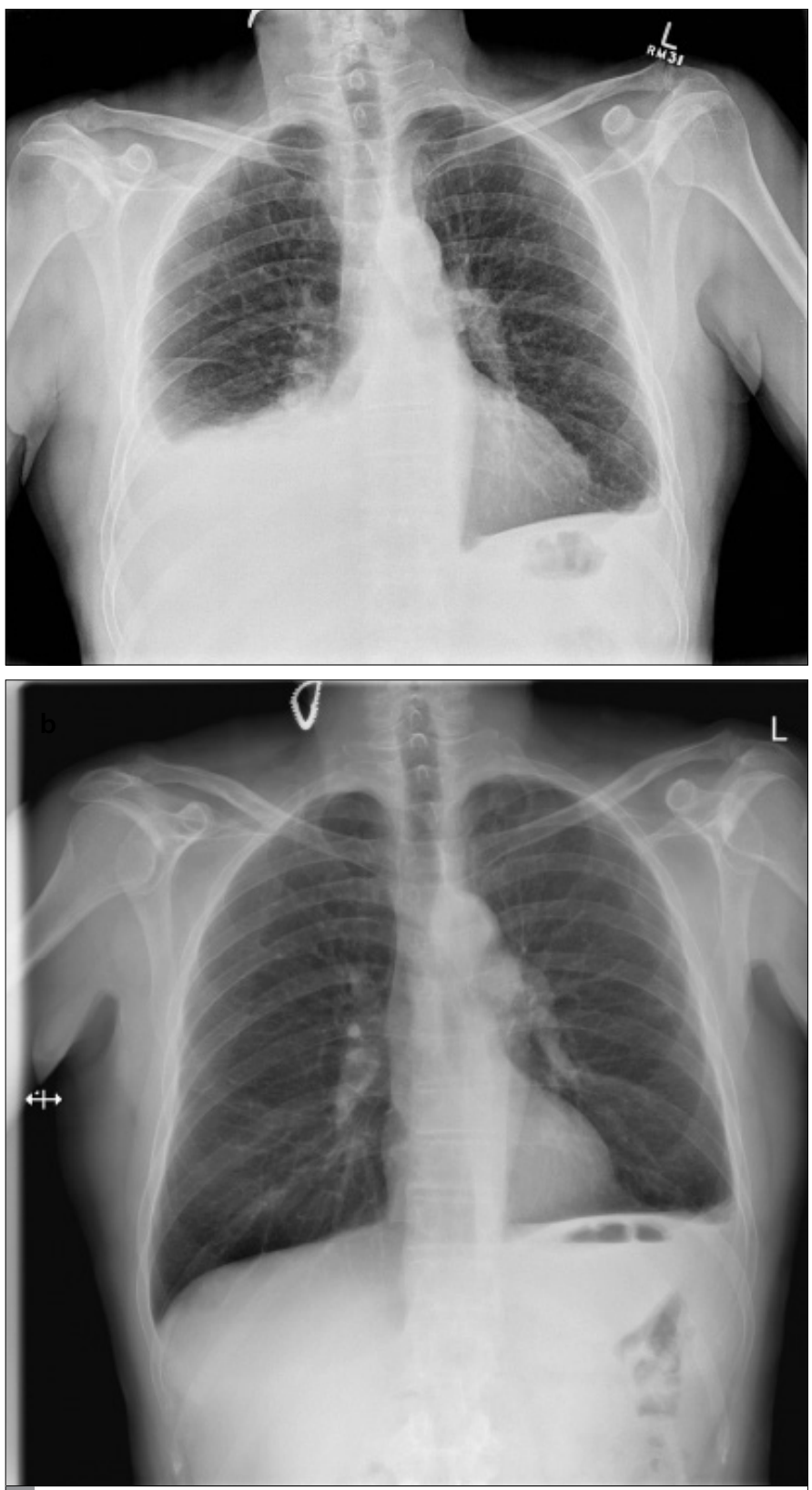

Figure 1. a, b. Chest radiograph showing blunting of the right costophrenic angle and left-sided pleural thickening during initial presentation (a), chest radiograph on clinical follow-up showing resolution of the chylothorax effusion post rituximab treatment (b)

ral biopsies both confirmed a low-grade B-cell non-Hodgkin's lymphoma with kappa light chain restriction and no expression of CD5, CD10, or cyclin D1. Lymphoscintigraphy identified chyle leak at the level of the T6/7 vertebrae (Figure 2). Positron-emission tomography scan found no focal tracer uptake.

He remained asymptomatic and required no chemotherapy. His chylothorax gradually increased but completely resolved after a trial of treatment with $2.7 \mathrm{GBq}^{131} \mathrm{I}$-rituximab. He remained well with no recurrence of pleural effusions 12 months (Figure 1) after the lymphoma diagnosis.

Informed consent has been obtained from the patient for this case report and for the images.

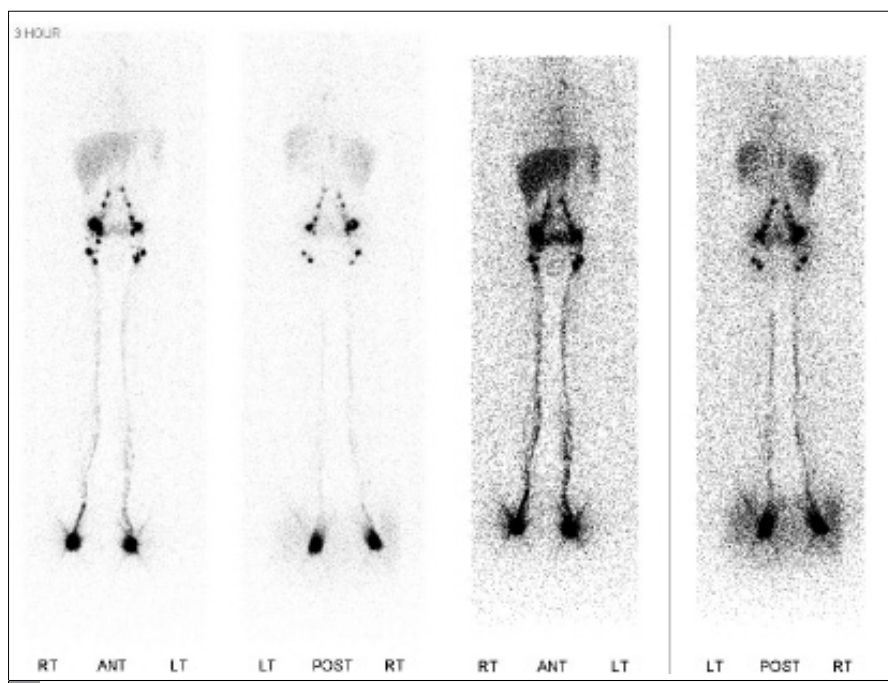

Figure 2. Lymphoscintigraphy using $99 \mathrm{Tm}$ colloid at $3 \mathrm{~h}$ demonstrating persistent focal accumulation of the tracer at the expected location of the thoracic duct at the T6/7 level, which persisted after delayed imaging for $6 \mathrm{~h}$, raising the possibility of a leak; however, there was no diffusion of the tracer into the effusion. The tracer appearance through major lymphatic channels of the legs to inguinofemoral lymph nodes and subsequently pelvic and intra-abdominal retroperitoneal nodes is normal. The appearance in the liver also suggests that diffusion of the tracer into the systemic circulation was unaffected

\section{DISCUSSION}

This is the first report of S. enteritidis empyema that preceded the diagnosis of malignancy and is also the first report of the successful control of lymphoma-associated chylothorax treated with radiolabeled rituximab.

Salmonella empyemas are rare. We found no other cases in an audit of 713 cases of culture-positive empyema in Western Australia (3). Although $S$. enteritidis is the most common serovar in causing enteric Salmonellosis, it only accounts for 7 of the 39 Salmonella empyema cases reported in literature $(1,2,4-7)$. There are no clinical, imaging, or pleural biochemical features that clearly distinguish Salmonella empyema from empyemas of other microbial causes. The diagnosis of Salmonella empyema should be considered in patients with pleural infection and recent enteric symptoms.

The rarity of $S$. enteritidis empyema and the high rate of pre-existing diseases in reported series suggest that the lymphoma and empyema in our patient are causally related. Whether Salmonella empyema is an early manifestation of occult lymphoma in our patient or if it triggered the subsequent development of lymphoma is intriguing. Our case illustrates that such patients warrant thorough screening and longer-term surveillance for cancer.

The treatment of Salmonella empyema should be similar to that for other pleural infections, and it requires systemic antibiotics and prompt drainage of the infected pleural material (8). A wide choice of antibiotics has been quoted in literature, although drugs with beta-lactam activity and fluoroquinolones are often preferred regimens for Salmonella empyema (4). Surgery may be needed when conservative treatment fails. The contemporary use of combined 
intrapleural tissue plasminogen activator and deoxyribonuclease therapy has significantly reduced the need for surgical drainage for empyema, but it has not been specifically tested in Salmonella empyema (9). The mortality of Salmonella empyema has been reported to be substantial, in cases of S. typhimurium infection in particular (4). It is unclear if this reflects the virulence of the organism or whether patients with significant comorbidity and risks of mortality are more susceptible to the organism.

Lymphoma-related chylothorax is often difficult to control, and a prolonged chyle leak has the potential to cause malnutrition and death. Compared with systemic intravenous use, single agent iodine-radiolabeled rituximab has been employed in cases of relapsed or refractory lymphoma with good responses and less myeloablative effects, thus preserving more aggressive retreatment options for future relapse (10). However, it has not been reported for the control of chylothorax. Our case suggests that this is an option worth exploring in future patients.

\section{CONCLUSION}

In patients with Salmonella empyema, further investigations for possible underlying occult malignancy are warranted. Our case suggested the need for extended surveillance and follow-up even if the initial screening is negative. In addition, radiolabeled rituximab may present a novel and minimally invasive option for recurrent chylothorax secondary to lymphoma.

Informed Consent: Written informed consent was obtained from patient who participated in this case.

Peer-review: Externally peer-reviewed.

Author contributions: Concept - G.C.Y.L.; Design - S.A., M.R.; Supervision G.Y.C.L.; Resources - S.A., M.R.; Materials - S.A., M.R.; Literature Search - S.A., M.R.; Writing - S.A., M.R.; Critical Reviews - G.C.Y.L.
Conflict of Interest: No conflict of interest was declared by the authors.

Financial Disclosure: The authors declared that this study has received no financial support.

\section{REFERENCES}

1. Cohen Jl, Bartlett JA, Corey GR. Extra-intestinal manifestations of Salmonella infections. Medicine (Baltimore) 1987; 66: 349-88. [CrossRef]

2. Saphra I, Winter JW. Clinical Manifestations of Salmonellosis in Man: An Evaluation of 7779 Human Infections Identified at the New York Salmonella Center. N Engl J Med 1957; 256: 1128-34. [CrossRef]

3. Brims FJH, Rosenstengal A, Yogendran A, Lee F, Franke A, Reid C. The bacteriology of pleural infection in Western Australia. Proceedings from Abstract Poster in American Thoracic Society Meeting San Diego, May 16-21, 2014.

4. De Lope ML, Batalha P, Sosa M, Rodriguez-Gomez F J, Sanchez-Munoz A, Pujol $E$ et al. Pleural Empyema due to Salmonella enteritidis in a non-immunocompromised patient. Eur J Clinical Microbiol Infect Dis 2004; 23: 792-3. [CrossRef]

5. Crum NF. Non-typhi Salmonella empyema: case report and review of the literature. Scand J Infect Dis 2005; 37: 852-7. [CrossRef]

6. Cistulli PA, Barnes DJ, Young GA. Salmonella empyema in a patient with lymphoma. Aust N Z J Med 1991; 21: 246-7. [CrossRef]

7. Lenhard RE Jr, Densen P, Lenhard RE. Salmonella empyema and Hodgkin's disease. South Med J 1975; 68: 363-6. [CrossRef]

8. Brims FJ, Lansley SM, Waterer GW, Lee YC. Empyema thoracis: new insights into an old disease. Eur Respir Rev 2010; 19: 220-8. [CrossRef]

9. Piccolo F, Pitman N, Bhatnagar R, Popowicz N, Smith NA, Brockway B et al. . Intrapleural tissue plasminogen activator and deoxyribonuclease for pleural infection. An effective and safe alternative to surgery. Ann Am Thorac Soc 2014; 11: 1419-25. [CrossRef]

10. Leahy MF, Seymour JF, Hicks RJ, Turner JH. Multicenter phase II clinical study of lodine-131- rituximab radioimmunotherapy in relapsed or refractory indolent non hodgkin's lymphoma. J Clin Oncol 2006; 24: 4418-25. [CrossRef] 